\title{
Productos Naturales PASUCHACA
}

\section{Natural Products PASUCHACA}

Carlos Bell ${ }^{1}$

\section{INTRODUCCIÓN}

"Pasuchaca", especie vegetal, autóctona del Perú perteneciente a la familia Geraniaceae, es una planta silvestre que crece en forma natural; es usada popularmente en nuestro país, bajo la forma de decocción de la planta entera, para el tratamiento de la diabetes; aunque un estudio realizado sólo con la raíz de esta especie, mostró tener efecto antiinflamatorio cuando se administró tópicamente en forma de emulsión farmacéutica ${ }^{(1)}$. $\mathrm{Su}$ nombre científico es Geranium dielsianum Knuth.

En efecto, la bibliografía existente muestra que, todos los estudios sobre la especie botánica Geranium dielsianum Knuth ("Pasuchaca"), han estado orientados a poner en evidencia sus conocidos efectos hipoglicemiantes. Sin embargo, un estudio realizado en la Facultad de Farmacia y Bioquímica de la UNMSM, ha dado a conocer un segundo efecto: el antiinflamatorio, el cual además, propone el uso de una especialidad farmacéutica químicamente estable, como alternativa para tratar casos de inflamaciones tópicas de tejidos blandos. En dicho estudio se trabajó exclusivamente con el extracto etanólico seco de la raíz de la especie citada, comprobándose su efecto antiinflamatorio en ratas albinas.

\section{REFERENCIAS HISTÓRICAS}

No se ha encontrado referencias históricas, ni pruebas materiales que demuestren que esta planta sea nativa del Perú, pero por información obtenida de botánicos con muchos años de experiencia, parece ser una especie vegetal exclusiva del Perú y no existen hasta la fecha, reportes de especies similares o de la misma especie en otros lugares del mundo. Según el doctor Fernando Montesinos, el primero en dar a conocer las virtudes curativas de esta planta fue el señor Oscar Silva ${ }^{(2)}$.

\section{ESTUDIO BOTÁNICO}

El Geranium dielsianum Knuth es una planta perenne, acaule, silvestre, que crece en forma espontánea. Su RAÍZ es típica o pivoteante. Sus HOJAS son basales, pubescentes, sostenidas por peciolos de $21 \mathrm{~m} \mathrm{~m}$ de largo, de disposición alterna, palmatipartidas en siete, dentilobulada, los lóbulos ampliamente cuneados, abonados los tres lóbulos del medio tridentados y los cuatro lóbulos laterales bidentados con estipulas pubescentes, concrescentes, corolino de 13 milímetros de largo. Sus FLORES se agrupan en inflorescencias; umbelas con pedúnculo floral de 10 milímetros de largo. Las flores son periánticas, hermafroditas, actinomorfas, presentan en sus bases cinco verticilos de brácteas corolinas. Cáliz dialisépalo, con cinco sépalos pubescentes oblongolanceolados. Corola dialipétala de tipo rosáceo, pentámera de color blanco, el pétalo presenta una uña corta, es glabro, entero y de forma abovada. Androcea, diplostémono, con 10 estambres libres dispuestos en dos verticilos, el verticilo externo más corto que el interno, con anteras ditésicas de color amarillo, dorsifijas, con filamento laminar acintado, ligeramente pubescente. Gineceo completo, ovario súpero pubescente de forma globosa, estilo céntrico, corto, pubescente, pentacarpelar, pentalocular, pentaovular, con cinco ramas estigmáticas, bífidas, petaloide.

Su FRUTO es esquizocárpico de tipo regma, que procede de un gineceo pluricarpelar con muchos estilos soldados entre sí, pero al madurar el fruto cada uno se separa en el correspondiente carpelo $^{(2)}{ }^{(5)}$.

\footnotetext{
${ }^{1}$ Doctor en Farmacia y Bioquímica

Docente Principal de UNMSM

Investigador del Instituto de Ciencias Farmacéuticas y Recursos Naturales "Juan De Dios Guevara" - UNMSM
} 


\section{UBICACIÓN SISTEMÁTICA}

Geranium dielsianum Knuth, de acuerdo con el Código Internacional de Nomenclatura Botánica (C.I.N.B.), se ubica:

DIVISÓN: Spermatophyta

CLASE: Dicotyledoneae (Magnoliopsida)

SUB CLASE: Rosidae

ORDEN: Geraniales

FAMILIA: Geraniaceae

GÉNERO: Geranium L.

ESPECIE: Geranium dielsianium Knuth

NOMBRE COMÚN: "Pasuchaca"

SINONIMIA: Pasuchaka, pasochaca ${ }^{(4)}$.

\section{DISTRIBUCIÓN GEOGRÁFICA}

La familia Geraniácea está conformada por unas 650 especies que habitan en todos los países del globo, particularmente en África del Sur.

En el Perú han sido identificadas 32 especies distribuidas a lo largo de los Andes, sobre los 3000 m.s.n.m ${ }^{(3)}$. La especie Geranium dielsianum Knuth crece de manera silvestre en el norte del país en los Departamentos de Cajamarca (Chota) y Piura (Ayabaca). Se recolecta en los meses de abril a mayo.

\section{ANTECEDENTES DE USO}

Geranium dielsianum Knuth, conocida como "Pasuchaca" es usada popularmente en el Perú, bajo la forma de cocción de la planta entera, para el tratamiento de la diabetes (no insulinodependiente). La parte usada para fines medicinales es la planta entera (raíces, hojas y flores) en cocimiento al 10\%: es decir, 10 gramos de planta seca por cada 100 mililitros de agua, filtrar y evaporar lentamente hasta la mitad del volumen.

El cocimiento también se puede preparar usando 10 gramos de planta seca por kilogramo de peso corporal, en cantidad suficiente de agua para mantener la concentración (10\%); calentar y evaporar lentamente hasta la mitad del volumen. En éste, el efecto hipoglicemiante es mayor ${ }^{(2)}$.

\section{FÍSICO - QUÍMICA}

Los estudios fisicoquímicos hechos en extractos a base de diversos disolventes revelan la presencia en la Pasuchaca de azúcares reductores; glicósidos antraquinómicos, antociánicos y saponímicos; taninos, flavonoídes, saponinas, carotenoides, mucílagos, aceites esenciales, resinas, grasas y ceras.

\section{FARMACOLOGÍA}

Estudios llevados a cabo en el Instituto Nacional de Perú reportaron que el extracto acuoso de "pasuchaca" produjo un efecto hipoglicemiante al ser administrados por vía oral a conejos a los cuales se les indujo diabetes experimental con Aloxano. La administración se efectuó una hora antes de cada determinación de glucosa a una dosis de $10 \mathrm{~g} / \mathrm{kg}$

En la universidad de Tokio, también se ha estudiado esta planta, en forma de extracto metanólico, el cual reporta un efecto inhibidor de pasuchaca sobre la actividad de la alfa-glucosidasa lo que contribuye al retraso de la digestión de los carbohidratos traduciéndose esto, en disminución de los niveles de glucosa en sangre.

El mecanismo exacto de la acción de la "'Pasuchaca" no se conoce. Los extractos acuosos muestran una marcada actividad hipoglucemiante, aun cuando no se conoce con exactitud cual es el componente responsable de esta acción; sin embargo se cree que los extractos interfieren la unión de la insulina a las proteínas plasmáticas dando como resultado una hormona libre o activa. Aumenta la utilización periférica de la glucosa e incrementa la capacidad de esta última por el músculo; inhibe la glucogénesis hepática aumentada en los diabéticos al aumentar la fijación de la insulina a sus receptores. Impide la resorción de la glucosa a través del epitelio tubular del riñón, eliminando mayor concentración de glucosa en la orina que la presentada en condiciones fisiológicas por los diabéticos. Favorece las funciones del páncreas ${ }^{(6)}$.

\section{USOS}

La "pasuchaca" es un efectivo hipoglucemiante, útil para combatir la diabetes juvenil, sin actividad insulínica así como la derivada del stress. No reemplaza a la insulina.

También puede ser usado como antiinflamatorio tópico en concentración al $1 \%$ en una emulsión farmacéutica. 


\section{TOXICIDAD}

"Pasuchaca" no ha mostrado ningún efecto tóxico en humanos.

Los ensayos de toxicidad aguda con los extractos acuosos muestran una DL50 de $35 \mathrm{~g} / \mathrm{kg}$. de peso corporal, lo que descarta toda posibilidad de efectos tóxicos a la dosis recomendada. Sin embargo, personas sensibles que presentan reacciones alérgicas o intolerancia deben de suspender el tratamiento.

\section{DOSIFICACIÓN}

"Pasuchaca" se presenta bajo la forma de cápsulas que contienen $100 \mathrm{mg}$ de extracto seco atomizado de toda la planta. La dosis recomendada es de 3 cápsulas al día, con las comidas, pudiendo ajustarse según necesidades individuales.

Como antiinflamatorio, se recomienda el uso tópico de crema con $1 \%$ de extracto etanólico de raíz de "pasuchaca", tres veces al día.

\section{CATEGORIA FARMACÉUTICA}

Hipoglicemiante y antiinflamatorio

\section{CONCLUSIONES}

Geranium dielsianum "pasuchaca", es una planta silvestre oriunda del Perú, que crece en forma natural.

Es considerada como la especie vegetal con mayor efecto hipoglicemiante, es decir que baja los niveles de glucosa en la sangre.

Un nuevo efecto se ha reportado: el antiinflamatorio

\section{AUTOR DE CORRESPONDENCIA}

Carlos Bell Cortez. Docente Principal de UNMSM

Investigador del Instituto de Ciencias Farmacéuticas y Recursos Naturales "Juan De Dios Guevara" - UNMSM

Decano de la Facultad de Ciencias de la Salud, Universidad María Auxiliadora, Av. Canto Bello 431- Ciudad Universitaria, Lima 36 - Perú. Teléfono: +51-1-3891212.

E-mail carlosbellcortez@yahoo.es

\section{BIBLIOGRAFÍA}

1. Bell C. Elaboración de crema dérmica con extracto etanólico de raíz de geranium dielsianum knuth ("pasuchaca"), efecto antiinflamatorio. Tesis de Maestría Facultad de Farmacia y BioquímicaUNMSM.2002. Lima.

2. Palacios V. Plantas Nativas Medicinales, CONCYTEC, 1era. Edición 1997, Ay B.S.S, pág.: $211-213$.

3. Sociedad Geográfica de Lima. Opúsculo sobre Geografía del Perú libro N.- 17. Anuario Geográfico. Opúsculo N.- 17.04. Síntesis Geográfica al 28.02.89. Lima.

4. SOUKUP, J. Vocabulario de los Nombres Vulgares de la Flora Peruana, Colegio Salesiano, 1986. Lima.

5. Domeren Ch. Atlas de Botánica. Ed. Jover. 1986. Barcelona.

6. Meyer, D. Diabetes en el Anciano. Diagnóstico y Tratamiento.- Tribuna Médica, No. 639, Tomo L VIII, Nº7.

Recibido: 08/06/2015

Aceptado: 25/06/2015 